\title{
VISITING SCIENTISTS PROVIDE CAPACITY DEVELOPMENT LESSONS LEARNED BY POGO AND SCOR
}

By Ed Urban and Sophie Seeyave

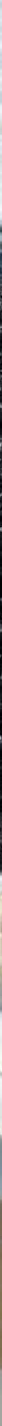


ABSTRACT. To enable the sustainable use of their ocean resources, capacity for ocean science and observations is important for every coastal nation. In many developing areas of the world, capability for ocean science and observations is not yet adequate to meet management needs. International organizations have employed a variety of capacity development approaches to assist developing countries in building selfsustaining ocean science and observational communities. This article describes the lessons learned from visiting scientist programs conducted for more than a decade by the Partnership for Observation of the Global Ocean (POGO) and the Scientific Committee on Oceanic Research (SCOR) that dispatched ocean scientists to developing countries to train hundreds of individuals in a variety of ocean science and observation topics and techniques. From these programs, SCOR and POGO have learned that training in-country has multiple benefits to trainees, host institutions, and trainers, benefits that are not achievable when students leave their countries. These benefits include more cost-effective training on issues relevant to the host institutions using locally available technology, as well as the ability to reach a large number of trainees. Lessons learned from the POGO and SCOR programs can be used to inform the future capacity-development activities of POGO and SCOR, as well as other organizations, to improve, enhance, and expand the use of in-country training and mentoring. Such approaches could contribute to the capacity development efforts of the UN Decade of Ocean Science for Sustainable Development.

\section{INTRODUCTION}

Capacity for ocean science-funding, ships and equipment, personnel-varies throughout the world, typically with greater capacity in developed regions and less capacity in developing regions (IOCUNESCO, 2020). Yet, greater scientific understanding of all areas of the global ocean is needed, particularly for management of each nation's ocean resources and protecting its ocean environment. Ideally, each nation with a coastline should have sufficient scientific capacity to understand ocean processes in areas under its management, and national resources should be used to sustain the ocean science community. Scientific capacity is also necessary for the deployment of ocean observing systems (Miloslavich et al., 2018) and for understanding of the observations collected. For countries without sufficient ocean research and observation capacity to match their needs, a variety of options are available to build their communities. For training, mentorship, and networking in ocean science, scientific meetings can be used to help reach students from developed and developing countries (Urban and Boscolo, 2013). Major international ocean research projects can provide platforms for capacity development over longer time periods (Morrison et al., 2013).

Programs that provide extended exposure of students to trainers increase the potential for education and networking. A common approach for developing capacity is to send students to developed countries to earn graduate degrees and then return to their home countries to work. The success of this approach depends on the availability of adequate salaries and jobs for returning graduates. Brazil, Chile, China, India, and some other middle-income countries have sent many students abroad for their educations and now have self-sustaining ocean science education systems. This approach has potential downsides, however, especially if the sending nations do not provide resources to attract students back to their home countries and/or students are trained to use equipment and techniques that are not available in their home countries. Students may decide to stay in the countries in which they did their training, resulting in "brain drains" from the scientific communities of their countries of origin.

A complementary approach, sending scientists to developing countries to mentor and teach, has some advantages and avoids the negative outcomes of sending students abroad for training. The Partnership for Observation of the Global Ocean (POGO) and the Scientific Committee on Oceanic Research (SCOR) have used this approach, through the Nippon Foundation (NF)-POGO Visiting Professorship, POGO Visiting Professor programs (2005-2014), and the SCOR Visiting Scholars Program (since 2009). SCOR and POGO have developed these complementary programs in response to the desire expressed by members of the two organizations to fill unmet training needs. SCOR and POGO collaborated on this article for Oceanography in order to compare our results and to develop common lessons learned for use by other organizations. It should be noted that SCOR and POGO are small nongovernmental organizations whose capacity development activities are focused on their missions of advancing ocean science and observations worldwide. Intergovernmental organizations, such as the Intergovernmental Oceanographic Commission, have the mission and resources to tackle broader societal issues related to, for example, the UN Sustainable Development Goals and environment and gender issues, although we will mention later some actions that SCOR and POGO could take to contribute to meeting societal needs.

Ensuring that scientists and institutions in developing countries are contributing to global networks is very important in capacity development for several reasons: (1) it can be a means of providing continued dissemination of knowledge, standards, and best practices in developing countries; (2) international networks can only be truly global if they include developing countries; (3) there are large gaps in observations and data that need to be filled to create the truly global observing networks required to address major scientific and societal issues, such as climate change, ecosystem health, and human health and safety; and (4) there are specific and pressing issues in developing countries, in particular, in Small Island Developing States (SIDS). In the context 
of the UN Sustainable Development Goals, such issues can only be addressed by scientists in those countries working with the international community.

\section{EXAMPLES OF INTERNATIONAL VISITING SCIENTIST PROGRAMS}

Many international organizations conduct scientific training programs in which an organization sends its own trainers (and sometimes contracted outside trainers) to conduct programs in specific areas of science. In ocean science, for example, the Intergovernmental Oceanographic Commission (IOC) offers training related to identification of harmful algal bloom organisms (http://hab.ioc-unesco.org/index.php? option=com_content\&view=article\&id= $13 \&$ Itemid=0). Another example is training by IOC's Ocean Teacher Global Academy (OTGA) (http://classroom. oceanteacher.org/) on a variety of topics relevant to IOC's mission. Upon request by its member states, the International Atomic Energy Agency (IAEA) provides training related to marine systems at its Marine Environmental Studies Laboratory in Monaco, as well as on site in countries around the world. These programs fill an important need for training in ocean science observations and monitoring, data management, disaster preparedness, and other purposes.

A complementary approach is to have open calls for scientists to teach and mentor in other countries. There is a long history of visiting scientist programs that issue open calls for interested scientists to apply to work outside their countries on a temporary basis. These programs select the expertise of their trainers based on the interests of host countries. The most prestigious program of this type is the Fulbright Scholars Program which, among other purposes, sends professors from the United States to teach in other nations of the world (see http://www.cies.org/). This program was established in 1946 and is sponsored through the US Department of State and host countries. Approximately 1,200 US Fulbright Scholars are sent each year to other countries, both developed and developing. Additionally, the program supports non-US scholars to work in the United States. The topics of these fellowships are identified by host countries, and calls for applications are issued on a regular basis. Yet, only a small number of each year's Fulbright Scholars are ocean scientists, and there is an unmet need for shorter-term visits in many developing countries.

\section{THE POGO AND SCOR VISITING SCIENTIST PROGRAMS}

POGO and SCOR have deployed visiting scientists in developing countries globally to increase the capacity for ocean science and observations. Table 1 provides the characteristics of the POGO and SCOR visiting scientist programs.

\section{NF-POGO and POGO Visiting}

\section{Professorship Programs}

The primary goal of the 2005-2007 Nippon Foundation (NF)-POGO Visiting Professorship Program (https://pogoocean.org/capacity-development/nfpogo-visiting-professorships/) was to contribute to long-term, sustained capacity development for ocean observations in developing countries, as well as to enhance networking among oceanographic institutes. The program allowed for extended visits of an experienced oceanographer (and supporting team) to a developing country to provide training and mentoring to young ocean scientists. The Nippon Foundation funded two Visiting Professors (VPs) per year. Each of the six VPs spent time with local scientists and students giving lectures; advising them on the purchase, maintenance, and operation of instrumentation; and performing fieldwork and analysis and interpretation of collected data. The program covered all expenses, including the purchase of specialized equipment when essential for the success of the program. In 2008, the Nippon Foundation and POGO redirected the funding to a different type of training program (see https://pogo-ocean.org/capacitydevelopment/centre-of-excellence/), and the NF-POGO VP program was replaced by a more modest VP program (https:// pogo-ocean.org/capacity-development/ pogo-visiting-professorship/) run and

TABLE 1. Characteristics of the Nippon Foundation-POGO Visiting Professorship (NF-POGO VP), POGO Visiting Professorship (POGO VP), and SCOR Visiting Scholar (SCOR VS) programs.

\begin{tabular}{|c|c|c|c|}
\hline $\begin{array}{c}\text { PROGRAM } \\
\text { CHARACTERISTICS }\end{array}$ & NF-POCO VP & POCO VP & SCOR VS \\
\hline Application process & $\begin{array}{l}\text { Annual call for applications from } \\
\text { prospective hosts }\end{array}$ & $\begin{array}{l}\text { Annual call for applications from } \\
\text { prospective hosts }\end{array}$ & $\begin{array}{c}\text { Annual call for applications from } \\
\text { prospective hosts and scholars }\end{array}$ \\
\hline Funding level & Up to US\$150K & Up to $\sim$ US\$7K & Up to US\$2.5K \\
\hline Expenses covered & $\begin{array}{l}\text { Travel and accommodation for } \\
\text { professor and supporting team, travel } \\
\text { for all students, equipment/books }\end{array}$ & $\begin{array}{l}\text { Travel for professor and travel for } \\
\text { some students }\end{array}$ & $\begin{array}{l}\text { Travel for professor and local } \\
\text { expenses up to } \$ 2.5 \mathrm{~K}\end{array}$ \\
\hline Duration & Up to 6 months & $2-3$ weeks $^{1}$ & 2 weeks to 2 months \\
\hline Topics & $\begin{array}{c}\text { Operational oceanography/ocean } \\
\text { observations }\end{array}$ & $\begin{array}{c}\text { Operational oceanography/ocean } \\
\text { observations }\end{array}$ & Any topic within ocean science \\
\hline
\end{tabular}


funded by POGO. For this new VP program, POGO issued an annual call for applications, open to potential hosts from any Official Development Assistance recipient country (as defined by the Organisation for Economic Co-operation and Development). In their applications, the hosts identified a VP, outlined the training course, and demonstrated its relevance to POGO and how it would contribute to sustained capacity building in ocean observing at the host institution. The funding was much more restricted than for the NF-POGO program (see Table 1), and preference was given to host institutions willing to demonstrate their strong commitment to the program by covering all local expenses of the VP. The POGO VP program was ended in 2014 due to changes in funding priorities within POGO.

\section{SCOR Visiting Scholar Program}

The SCOR Visiting Scholar program (https://scor-int.org/work/ capacity/ visiting-scholars/) was initiated in 2009, inspired by the POGO VP program described above. SCOR Visiting Scholarships are awarded to scientists who train and mentor students and early career scientists in developing countries. SCOR provides a smaller amount of funding per Scholar (US\$2,500) than was provided through the POGO VP program. A call is made annually for both Visiting Scholars and host institutions, and the SCOR Committee on Capacity Building selects recipients. SCOR has received 3-30 applications per year and has awarded 1-7 scholarships per year, depending on the qualifications of applicants, with four scholarships awarded in 2021. A Visiting Scholar may apply without first identifying a host institution, and a host institution may apply without identifying a scientist to visit, so that SCOR can do the matching. However, most applicants arrange matches before applying. Funds for the SCOR program are derived from US National Science Foundation grants, contributions from national SCOR committees, and support raised through

\section{CASE STUDY 1. NF-POGO Visiting Professor at the National Institute of Oceanography, Kochi (India)}

One of the first Visiting Professors to participate in the Nippon Foundation (NF)POGO program in 2005 was the late Trevor Platt (at the time affiliated with the Bedford Institute of Oceanography, Canada), who, with a team of colleagues, provided training to 24 students from India, Vietnam, Thailand, and Tanzania at the National Institute of Oceanography (NIO), in Kochi, India. Specialized equipment (a high performance liquid chromatography instrument, incubators, a spectrophotometer), as well as textbooks, reprints, and software, were procured for NIO as part of the program. These assets were seen as critical to the training and also to the continuation of work in the subject area by the trainees.

The participants were trained in the use of the equipment and the interpretation of remotely sensed ocean color data as a tool for the analysis of marine ecosystems. They worked with Prof. Platt on the design and execution of five small research projects, on the presentation of results at seminars, on preparation of research papers and project proposals, and on strategies for establishing long-term observations and research in biological oceanography of the Indian Ocean region.

This program was successful in several ways. First, several alumni went on to very productive careers and held senior positions in government, research, and academia. Second, a long-term collaboration between the Visiting Professor and the trainees and the host institute led to subsequent training programs-some funded by NF-POGO (e.g., the NF-POGO Regional Training Program in 2011) and some by other organizations, and most importantly, by the country itself-as well as to subsequent joint research projects between Prof. Platt and some of the former trainees. The NF-POGO Alumni Network for Oceans (NANO), initiated in 2010, has provided further support post-training and initiated joint activities for and by the alumni, including regional and global research projects and outreach activities.

Finally, Prof. Platt and NIO senior scientists and management were unanimous in their praise of the value and importance of the program. The alumni have often provided positive feedback on the training and subsequent collaborations and the impacts they have had on their careers (George and Menon, 2021). In the words of one trainee, Grinson George, this capacity building "marked a change in the field of ocean optics in India and [its] user group and led to career growth and improvement in science individually, institutionally, and on [a] national basis."

The key to the success of this program was twofold: the holistic approach, combining training with the provision of relevant and required instrumentation, books, and other materials, coupled with the long-term strategy of continuous engagement between the Visiting Professor and the trainees, which will prolong and enhance the legacy of the training for years and even decades.

Laboratory techniques were demonstrated during the NF-POGO Visiting Professorship in Kochi, India, in 2005. Photo credit: Phan Minh Thu

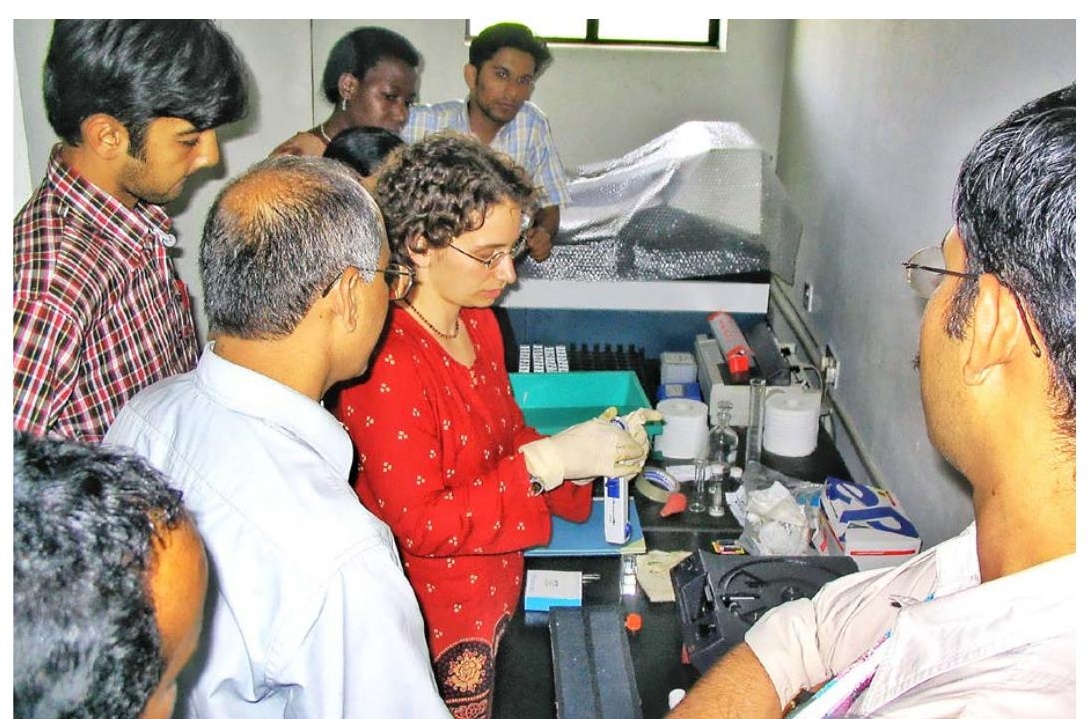


crowdfunding campaigns. Hosts are expected to provide lodging to show their commitment to the visit. Visiting Scholars must spend at least two weeks at the host institution, but can stay longer if the host is willing to provide lodging and the local subsistence costs are low. The longest visit so far has been two months. SCOR does not require that the Visiting Scholar come from a country that participates in SCOR or that the host country participate in SCOR (i.e., has a national SCOR committee that pays annual dues). SCOR appointed 45 different Visiting Scholars between 2009 and 2020). Of these, three Visiting Scholars served twice and another served three times.

\section{RESULTS OF THE PROGRAMS}

Both POGO and SCOR conduct a variety of surveys of their visiting scientists, trainees, and host institutions to evaluate the programs and identify any changes that would help improve the programs. The detailed results of the visiting scientist programs are available in the online supplementary materials.

\section{Survey of NF-POGO and \\ POGO Visiting Professors \\ and SCOR Visiting Scholars}

Figure 1 combines data from the POGO and SCOR programs to provide a global picture of "sending" and "hosting" countries for the two programs. Nine of the
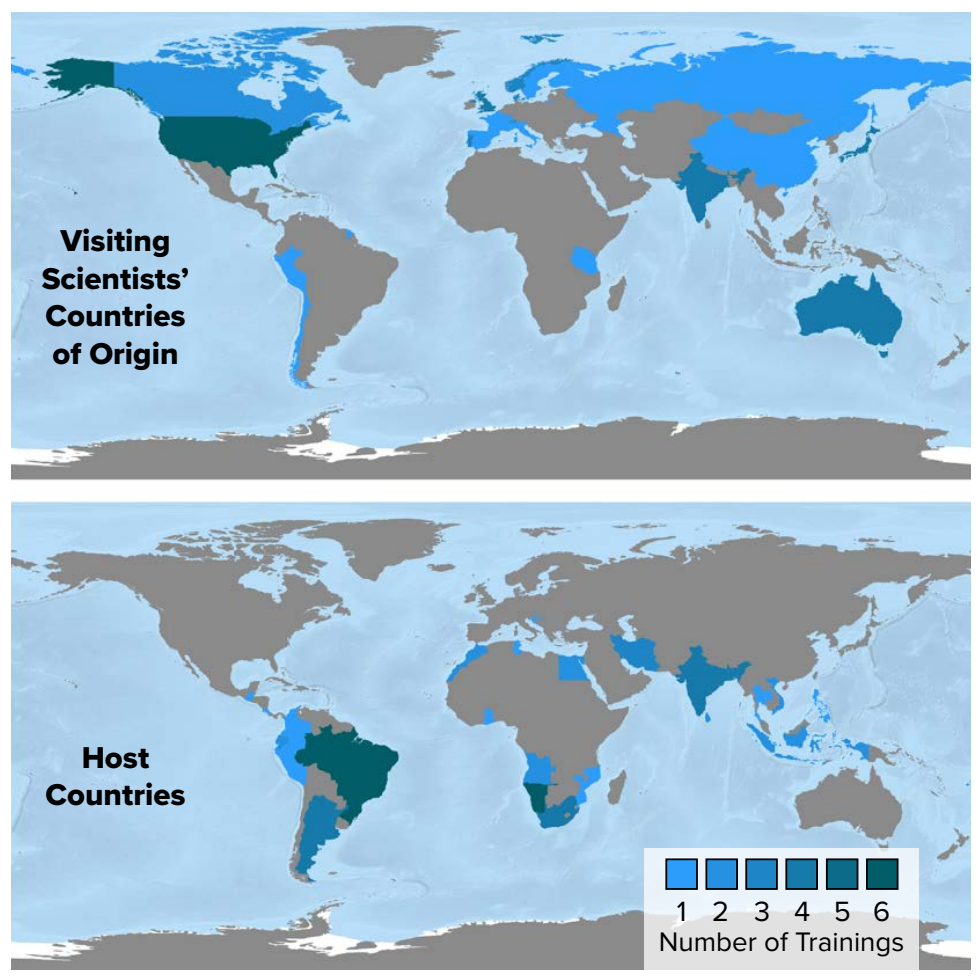

FIGURE 1. Visiting scientists' countries of origin of and their host countries for SCOR and POGO visiting scientist programs. Image credit: Lilian Krug

TABLE 2. Demographics of visiting scientists.

\begin{tabular}{|r|c|c|}
\cline { 2 - 3 } \multicolumn{1}{c|}{} & $\begin{array}{c}\text { POGO and NF-POGO } \\
(\mathbf{n}=\mathbf{1 4})\end{array}$ & $\begin{array}{c}\text { SCOR }^{\mathbf{1}} \\
\mathbf{( n = 4 5 )}\end{array}$ \\
\hline Gender distribution & $\begin{array}{c}\text { Male }=93 \% \\
\text { Female }=7 \%\end{array}$ & $\begin{array}{c}\text { Male }=67 \% \\
\text { Female }=33 \%\end{array}$ \\
\hline Most common age bracket & Not known & $\begin{array}{c}\text { Male: } 60-69 \text { years } \\
\text { Female: } 40-49 \text { years }\end{array}$ \\
\hline
\end{tabular}

The data presented include 2020 SCOR Visiting Scholars who were selected, but who have not yet traveled to their host countries because of the COVID-19 pandemic

SCOR Visiting Scholars have been from developing countries, and it is notable that India and Peru have been both sending and hosting nations, indicating that they have enough expertise on some topics to send scientists to other developing countries, but may lack expertise on other topics. Table 2 provides other demographics for the visiting scientists. Table 3 presents information about the results of the training, based on SurveyMonkey questionnaires returned by visiting scientists. The results are generally similar among the programs.

\section{Surveys of Trainees}

A survey was sent to individuals who had received training from POGO Visiting Professors more than five years previously. SCOR has distributed its survey since 2018, soon after the courses; no results are available for the earliest years of the program. Table 4 shows the demographics of the POGO and SCOR trainees. For analysis of POGO results, only data from the NF-POGO Visiting Professorships are considered, because very few responses were received for the POGO VP program.

POGO asked its trainees whether they were still living in their home country and, if so, whether they had been living there the entire time since their training. The question was to allow comparison of the effects of in-country training with those of training abroad, with respect to possible "brain drain" of recently trained young scientists. More than $90 \%$ of the trainees of NF-POGO VPs were still living in their home country, and another $5 \%$ who were not currently in their home countries indicated that they intended to return.

In terms of the medium-term impacts of the NF-POGO VP program on the trainees' education, skills, and careers, the categories that received the highest scores were:

- The training enabled me to participate in new research projects.

- The training enabled me to implement new techniques, use new equipment, and/or use new software/models 
that were previously unavailable at my institute.

- I have continued to collaborate with scientists I met during the training (e.g., supervisor, instructor, or other trainees).

Scores were relatively low regarding longer-term career impacts, indicating that the training had little direct impact on a trainee's ability to obtain a permanent position as a researcher or lecturer in marine science or a related field. Scores were even lower for other types of positions (consultancy, management, policy) or for improvements to their working conditions. Regarding the dissemination of knowledge gained, high percentages of respondents had given seminars or lectures based on the training (85\%) and/ or supervised students (undergraduate or postgraduate) since receiving the training (78\%). A lower, but still significant, percentage of respondents supervised colleagues (68\%). More than $95 \%$ of respondents who had supervised or mentored others stated that the knowledge gained during the training had been passed on. In terms of products, the most produced outputs ( $>2$ per respondent) were conference presentations (oral, then poster), peer-reviewed research articles, then non-peer-reviewed research articles.

SCOR's survey of trainees is aimed at evaluating the satisfaction of the trainees with their training and the benefits they thought they gained from the training, soon after the training occurred. For training by SCOR Visiting Scholars, most of the trainees (65\%) thought the courses were the right duration and the right level of difficulty (69\%), although some trainees would have liked a longer and/or less difficult training (the length of courses is determined by the Visiting Scholar and the host). A majority of trainees expressed that their expectations were met $(85 \%)$ and that the Visiting Scholars knew their subject matter well (100\%), were enthusiastic (97\%), and were easy to understand (84\%). The trainees expressed that the major benefits from the training were gaining new information and ideas for research, learning new research techniques, and networking with the Visiting Scholar. Trainees reported that they would pass on the knowledge gained to their colleagues and students through presentations and articles. Examination of data from the trainees indicates that

TABLE 3. Results of training offered by visiting scientists.

\begin{tabular}{|c|c|c|}
\hline & $\begin{array}{c}\text { POGO and NF-POGO (n } \\
=14)\end{array}$ & $\begin{array}{c}\text { SCOR } \\
(n=24)^{1}\end{array}$ \\
\hline Number of trainees & 306 & $495^{2}$ \\
\hline Cost per trainee & $\begin{array}{l}\text { US } \$ 235 \text { POGO VP to } \\
\$ 6,169^{3} \text { for } N F-\text { funded } \\
\text { program }\end{array}$ & $\begin{array}{c}\text { US } \$ 155 \text {, } \\
\text { assuming } 495 \text { trainees }\end{array}$ \\
\hline $\begin{array}{r}\text { Visiting scientists who had kept } \\
\text { in touch with trainees at the time } \\
\text { they answered the survey }\end{array}$ & $\begin{array}{l}100 \% \text {, with } 70 \% \text { at least } \\
\text { once every three months }\end{array}$ & $\begin{array}{c}96 \% \text {, with } 62 \% \text { at least once } \\
\text { every three months }\end{array}$ \\
\hline $\begin{array}{l}\text { Reason for keeping in } \\
\text { touch with trainees: }\end{array}$ & & \\
\hline Continued research collaborations & $90 \%$ & $75 \%$ \\
\hline $\begin{array}{r}\text { To plan another research } \\
\text { visit or exchange }\end{array}$ & $70 \%$ & $38 \%$ \\
\hline To provide continued mentoring & $70 \%$ & $62 \%$ \\
\hline To provide reference letters & $50 \%$ & $38 \%$ \\
\hline \multirow{3}{*}{$\begin{array}{l}\text { Three most important benefits } \\
\text { gained by visiting scientists }\end{array}$} & $\begin{array}{l}\text { 1. The training led to another } \\
\text { visit or exchange of a } \\
\text { student or instructor }\end{array}$ & $\begin{array}{l}\text { 1. The training provided } \\
\text { personal satisfaction or } \\
\text { enjoyment }\end{array}$ \\
\hline & $\begin{array}{l}\text { 2. The training provided } \\
\text { personal satisfaction or } \\
\text { enjoyment }\end{array}$ & $\begin{array}{l}\text { 2. The training broadened } \\
\text { my cultural horizons }\end{array}$ \\
\hline & $\begin{array}{l}\text { 3. The training led to } \\
\text { continued research } \\
\text { collaborations }\end{array}$ & $\begin{array}{l}\text { 3. The training led to } \\
\text { continued research } \\
\text { collaborations }\end{array}$ \\
\hline
\end{tabular}

2009-2019 Visiting Scholars who responded to the survey

Estimated. SCOR Visiting Scholar hosts are asked to indicate the number of trainees they were involved with at the host institution $(1-5,6-10,11-20$, and $>20)$. Using this information, it can be estimated that the 24 SCOR Visiting Scholars who answered the survey interacted with at least 309 individual students and other trainees, assuming the bottom figure in each range of trainees (i.e., 1, 6, 11, and 20). The median number of trainees was 11. If this median number of trainees is representative of the 21 Visiting Scholars who did not answer the survey, it can be estimated that the total number of trainees was 495 for the 45 Visiting Scholars.

Included equipment, supplies, and publications purchased by the program for continued use by the host institution.

TABLE 4. Demographics of trainees (based on the subset of trainees who responded to surveys).

\begin{tabular}{|c|c|c|}
\hline & $\begin{array}{l}\text { NF-POCO } \\
(n=41)\end{array}$ & $\begin{array}{c}\text { SCOR } \\
(n=81)\end{array}$ \\
\hline Gender distribution & $\begin{array}{c}\text { Male }=78 \% \\
\text { Female }=22 \%\end{array}$ & $\begin{array}{c}\text { Male }=40 \% \\
\text { Female }=60 \%\end{array}$ \\
\hline Most common age bracket & $21-30$ years & $21-30$ years \\
\hline Most common career category & Researcher & Student \\
\hline Most common education level & Master's level & Master's level \\
\hline $\begin{array}{r}\text { Percentage of trainees still living in } \\
\text { their home countries }\end{array}$ & $90 \%$ & Not assessed \\
\hline
\end{tabular}


level for all trainees. Training by Visiting Scholars in the language of the host country was helpful, when this was possible, and training in English for trainees whose first language was not English resulted in less successful results.

\section{Survey of Visiting Scientists' Hosts}

The home institutions of former POGO trainees and other institutions that have benefited from a variety of POGO training programs were surveyed, and the highest-scoring impacts (with scores of more than 4 out of 5) were:

- Enabling the institute's staff and students to benefit from the new knowledge and skills gained by the POGO trainees through seminars, practical sessions, or mentoring provided at the institute by the trainee

- Broadening the scope of oceanographic research conducted by the institutewhich is also evidence of "sustained capacity building," whereby a new area of research is implemented and maintained as a result of the training

- Providing connections with scientists in other countries who enabled the institute to participate in international or regional projects or networks

These results corroborate the findings from separate surveys addressed to trainees that showed that the trainees were passing on the knowledge gained and also imply that the institutes are providing support (e.g., infrastructure, staff) to sustain new areas of research. These findings support the conclusion that POGO training programs fulfilled their objectives of leading to sustained capacity building. Establishment of new observation programs in under-observed parts of the global ocean is another major objective of POGO training programs, although this is not easy to accomplish due to the significant funding and infrastructure requirements of ocean observing programs. It is therefore a very satisfactory result that the respondents feel that to a large extent this goal has been achieved (with the caveat that only 11 institutions responded).
Host institutions for SCOR Visiting Scholars were also surveyed using a SurveyMonkey questionnaire, starting in 2013 for 2009-2012, and annually thereafter for 2013-2019. Responses have been received from 13 of the 38 host institutions ( $34 \%$ response rate). One hundred percent of the respondents reported that they had been in touch with their Visiting Scholars for further mentoring and to continue research collaboration as well as to plan additional research visits or exchanges. Hosts reported that both students and staff benefited from interaction with the Visiting Scholar. Some of the hosts would have liked SCOR to have paid for more local costs and not primarily airfares. The highest-scoring impacts reported by host institutions (with scores of more than 4 out of 5) were:

- The training enabled us to learn new research and/or observation techniques.

- The training enabled us to implement and teach a new module/class as part of a higher education program.

- The training provided connections with scientists in other countries who enabled our institute to participate in international or regional projects or networks.

\section{LESSONS LEARNED}

POGO and SCOR learned that visiting scientist programs provide a variety of benefits not available through the other approaches mentioned above:

- There is an available pool of individuals who are passionate about teaching and mentoring and interested in working in developing countries for short periods (several weeks to, in some cases, months). The availability of qualified trainers exceeds the availability of funding to support them to do the training.

- Requiring hosts to provide some local costs is not a barrier to finding hosts, in most cases.

- A larger number of trainees can be reached per dollar/euro/pound spent when visiting scientists conduct their training in developing countries.
- In-country training reduces the likelihood of "brain drain."

- Training topics and techniques can be tailored to the host institution/country, using available technology to study topics and areas of greatest relevance to the institution and country. Zavaleta et al. (2020) provide helpful suggestions for making field courses more inclusive and diverse and for reducing barriers to underserved students.

- Visiting scientists gain a greater understanding of the opportunities and challenges faced by the host institutions/ countries and may become committed to continuing involvement with their host institutions.

- The trainer can attract other visiting scientists to work in the host country.

- Working with fixed budgets for capacity building, compromises have to be made between the number of trainees, the duration of the training, and the distances trainees (and instructors) can afford to travel. Because travel and accommodation costs are low in developing countries, visiting scientist programs offer the advantage of being relatively low cost per trainee. Longerterm programs that include new equipment for a host institution have significant advantages in terms of contact time and the capabilities that remain after the trainer leaves. These benefits must be balanced against higher costs per student.

- Training outcomes can be enhanced by trainers staying in touch with trainees and the host institution, which seems to occur with the SCOR and POGO programs.

- Trainers should be prepared to deal with heterogeneous groups of trainees. Ideally, the training should be adapted following an assessment of the experience and abilities of the trainees. Trainers with extensive experience in teaching and mentoring in developing countries can often quickly assess the teaching situation in a new country and adapt their training appropriately. It may be necessary to provide entry- 
level training for some trainees.

- There is some value in sending several visiting scientists to the same institution to create a sustained relationship.

- Visiting scientist programs could be facilitated by any organization, university, or research institution with a small amount of funding provided, leading to opportunities for their scientists to study processes in new areas, make new research partnerships, recruit new graduate students, and get excited about capacity development.

\section{THE FUTURE}

Training in ocean science and observations in developing countries is more important than ever. Visiting scientist programs could help developing countries address training needs related to fulfilling Sustainable Development Goals, aspects of the Convention on Biological Diversity, and participation in the UN Decade of Ocean Science for Sustainable Development. Such programs could be developed by the UN, IOC, and other organizations that do not yet have them. Universities and research institutions could develop visiting scientist programs to contribute to these international initiatives. The capacity exists and the training needs require a significantly larger number of visiting scientists than can be supported by SCOR and POGO.

Capacity development is a central element of the UN Decade of Ocean Science for Sustainable Development (Ryabinin et al., 2019; see https:// unesdoc.unesco.org/ark:/48223/pf0000265198), and SCOR- and POGO-type visiting scientist programs could be applied to many of its focus areas. The UN Decade is expected to increase investment and collaboration across ocean disciplines and across stakeholders, providing new opportunities for visiting scientist programs, and such programs could also contribute to implementation of the Global Ocean Observing System Essential Ocean Variables (Bax et al., 2018).

\section{POGO Visiting Professors Program}

POGO does not currently offer a visiting scientist program but uses its capacitybuilding budget to facilitate individual visits with a more flexible format. With the exception of the POGO-SCOR fellowship program, the allocated funds are pooled to allow POGO members

\section{CASE STUDY 2. Development of University of Namibia's Henties Bay Campus as a National Center for Ocean Science with Potential to Attract International Scientists}

SCOR sent Kurt Hanselmann, a microbial geoecologist from ETH Zurich (Switzerland), to the University of Namibia in 2010 and 2011, in response to the university's application to host a Visiting Scholar to teach biological and chemical oceanography. Dr. Hanselmann's experience as a Visiting Scholar led him to gather used laboratory equipment in Europe and send it to the University of Namibia on German research vessels to help equip the laboratories at Henties Bay. He also sought and received funding from the Agouron Institute and the Simons Foundation (through SCOR) and ETH Zurich to create a Regional Graduate Network for Oceanography (RGNO) based at the University of Namibia. (The RGNO concept was developed by SCOR in 1998: see https://scor-int.org/SCOR_CB/Bellagio_Report.pdf). The main activity of the RGNO has been to create annual Ocean Research Discovery Camps as a cooperative effort between the University of Namibia and the National Marine Information and Research Centre (NatMIRC) of Namibia's Ministry for Fisheries and Marine Resources. The camps bring together students and instructors from around the world (especially from Africa) to learn about the unique Benguela Current System. Some 63 research students and 32 instructors have participated in the courses so far. NatMIRC contributes to the courses by offering a few days of experience on its research vessel Mirabilis and by hosting a final research symposium each year at which students present the results of their research. Six Research Discovery Camps have been held so far, and funding will allow at least three additional courses. The courses were organized by Chibo Chikwililwa (University of Namibia)* and Richard Horaeb and Deon Louw (both at NatMIRC). The SCOR Committee on Capacity Building reviewed the progress and outcomes of the Research Discovery Camps in 2017 and recommended that they continue. The lessons learned from this visiting scientist experience are the following: (1) supporting scientists to teach and mentor in other countries can spark their enthusiasm for additional work at their host institutions, (2) a visiting scientist can stimulate increased cooperation among institutions in the host country, (3) institutions that have facilities adjacent to interesting marine systems can attract visiting scientists, and (4) visiting scientists can help to develop persistent capacity for future training.

${ }^{*}$ Dr. Chikwililwa died in June 2021 and will be greatly missed by organizers of this program.

Research Discovery Camp participants are gathered on the aft deck of R/V Mirabilis of the Namibian National Marine Information and Research Centre (NatMIRC). Photo credit: Marion Jaussi

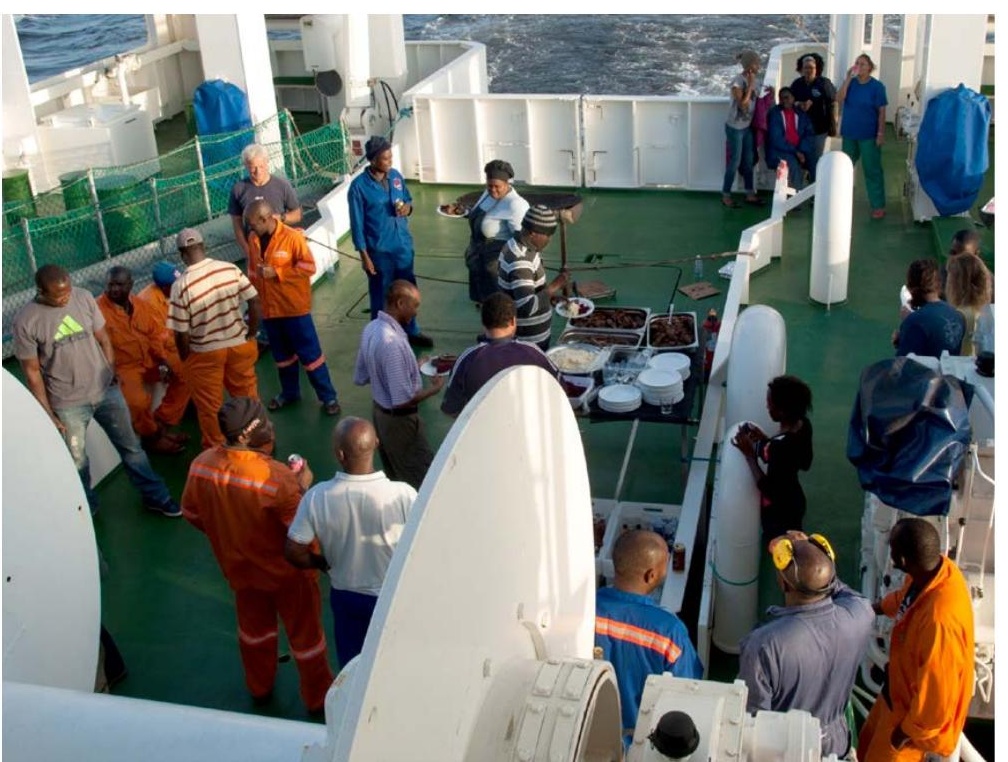


to apply for funding for a training program of their choice. Since 2015, these funds have been used to support training of early career scientists in Australia, Benin, China, India, the Netherlands, and the UK, and also onboard an Atlantic Meridional Transect cruise. POGO believes that this method responds to the needs of its members, which are providing the funding through payment of membership dues. It allows the flexibility to allocate funds where there is (1) an identified need, (2) a motivated teacher or team of instructors who are ready to provide the training, and (3) an existing framework for the capacity-building program. It also allows POGO to pool its resources with other organizations, as many of the initiatives are co-funded, and a modest amount of seed funding from one organization can attract more significant funding from others.

\section{SCOR Visiting Scholars Program}

From the number of applications SCOR receives, it is obvious that the interest in serving in developing countries is great, although the number of qualified individuals applying in 2021 decreased, perhaps due to the uncertainty caused by the COVID-19 pandemic. The need was already obvious, but even more so in the context of the UN's 2030 Agenda and its Sustainable Development Goal 14 (Life Below Water), as well as the UN Decade of Ocean Science for Sustainable Development. SCOR will seek to increase the number of SCOR Visiting Scholars over time so that many more people who are interested and qualified to teach/ mentor/impart knowledge can use their skills. In the future, SCOR will:

- Seek funding for trainees of SCOR Visiting Scholars to make short visits for training and internship at the Visiting Scholar's institution

- Encourage Visiting Scholars to maintain contact with host institutions and perhaps make second visits

- Better identify countries and institutions that can benefit from the program but that have not yet participated
- Integrate the Visiting Scholars program better with other SCOR capacitydevelopment activities, such as its Regional Graduate Networks of Oceanography (see https://scor-int.org/ work/capacity/rgno/)

A strategy that maintains more collaborative, continuing partnerships between visiting scientists and people at the host institutions would benefit SCOR and POGO. Approaches to ensure such follow-up by visiting scientists could include their serving as mentors for trainees' master's or $\mathrm{PhD}$ thesis research and working on papers together-although this has often been a natural outcome of the visits without being a formal requirement or recommendation. It would also be useful to make the courses given by visiting scientists available as resources through an open-access platform. The OceanTeacher Global Academy (OTGA: https://classroom.oceanteacher.org/) could provide such a platform to upload videos, PowerPoints, and other training materials so that the benefit of the visiting scientist program to a given institution goes beyond the time of the visit and beyond the group of trainees. Courses can be offered in different languages, helping to overcome language barriers. The SCOR and POGO websites could provide pages that list the topics/ courses given by visiting scientists, linked to the OTGA, where the full resources could be archived. @

\section{SUPPLEMENTARY MATERIALS}

Detailed results of the visiting scientist programs are available at https://doi.org/10.5670/oceanog.2021.306.

\section{REFERENCES}

Bax, N.J., W. Appeltans, R. Brainard, J.E. Duffy, P. Dunstan, Q. Hanich, H. Harden Davies, J. Hills P. Miloslavich, F.E. Muller-Karger, and others. 2018. Linking capacity development to GOOS monitoring networks to achieve sustained ocean observation. Frontiers in Marine Science 5:346, https://doi.org/ $10.3389 /$ fmars.2018.00346.

George, G., and N.N. Menon. 2021. NF-POGO Initiatives in India: Visiting Professorship of Prof. Trevor Platt, NANO regional projects, SAFARI and beyond. NANO News: NF-POGO Alumn E-Newsletter 20:30-32, https://nf-pogo-alumni.org/ newsletters/nano-news-20/.

IOC-UNESCO. 2020. Global Ocean Science Report 2020-Charting Capacity for Ocean Sustainability. K. Isensee, ed., Paris, UNESCO Publishing, 244 pp., https://gosr.ioc-unesco.org/.
Miloslavich, P., S. Seeyave, F. Muller-Karger, N. Bax E. Ali, C. Delgado, H. Evers-King, B. Loveday, V. Lutz, J. Newton, and others. 2018. Challenges for global ocean observation: The need for increased human capacity. Journal of Operational Oceanography 12:S137-S156, https://doi.org/ 10.1080/1755876X.2018.1526463.

Morrison, R.J., J. Zhang, E.R. Urban Jr., J. Hall, V. Ittekkot, B. Avril, L. Hu, G.H. Hong, S. Kidwai, C.B. Lange, and others. 2013. Developing human capital for successful implementation of international marine scientific research projects. Marine Pollution Bulletin 77:11-22, https://doi.org/10.1016 j.marpolbul.2013.09.001.

Ryabinin, V., J. Barbière, P. Haugan, G. Kullenberg, N. Smith, C. McLean, A. Troisi, A. Fischer, S. Aricò, T. Aarup, and others. 2019. The UN Decade of Ocean Science for Sustainable Development.

Frontiers in Marine Science 6:470, https://doi.org/ 10.3389/fmars.2019.00470.

Urban, E.R. Jr., and R. Boscolo. 2013. Using scientific meetings to enhance the development of early career scientists. Oceanography 26(2):164-170, https://doi.org/10.5670/oceanog.2013.16.

Zavaleta, E.S., R.S. Beltran, and A.L. Borker. 2020. How field courses propel inclusion and collective excellence. Trends in Ecology \& Evolution 35(11):953-956, https://doi.org/10.1016/ j.tree.2020.08.005.

\section{ACKNOWLEDGMENTS}

SCOR acknowledges support for its Visiting Schola Program from the US National Science Foundation (Grants OCE-0813697, OCE-1124729, OCE-1419950, OCE-1724881, OCE-2027831), national SCOR committees, the Intergovernmental Oceanographic Commission of UNESCO, and from individuals (many of them former SCOR Visiting Scholars) who contributed support through crowdfunding. POGO acknowledges the generous support of the Nippon Foundation provided since 2005 for the NF-POGO capacity building program, as well as the contributions of POGO members that support additional training grants. SCOR and POGO especially thank the visiting scientists who are the foundation of our programs, beginning with the late Trevor Platt, who was the first POGO Visiting Professor and who embodied the spirit of mentorship that is the basis of our capacity development efforts.

\section{AUTHORS}

Ed Urban (ed.urban@scor-int.org) was Executive Director, Scientific Committee on Oceanic Research (SCOR), Robinson Hall, University of Delaware,

Newark, DE, USA. Sophie Seeyave (ssve@pml.ac.uk) is Chief Executive Officer, Partnership for Observation of the Global Ocean (POGO), Plymouth Marine Laboratory, Plymouth, UK.

\section{ARTICLE CITATION}

Urban, E., and S. Seeyave. 2021. Visiting scientists provide capacity development: Lessons learned by POGO and SCOR. Oceanography 34(3):44-52, https://doi.org/10.5670/oceanog.2021.306.

\section{COPYRIGHT \& USAGE}

This is an open access article made available under the terms of the Creative Commons Attribution 4.0 International License (https://creativecommons.org/ licenses/by/4.0/), which permits use, sharing, adaptation, distribution, and reproduction in any medium or format as long as users cite the materials appropriately, provide a link to the Creative Commons license, and indicate the changes that were made to the original content. 